\title{
Anti-c-fms Monoclonal Antibody AMG 820
}

National Cancer Institute

\section{Source}

National Cancer Institute. Anti-c-fms Monoclonal Antibody AMG 820. NCI Thesaurus.

Code C98295.

A fully human IgG2 monoclonal antibody against the colony-stimulating factor-1 (CSF-1

or M-CSF) receptor c-fms (or CSFR1), with potential antineoplastic activity. Upon

administration, anti-c-fms monoclonal antibody AMG 820 binds to and blocks c-fms,

thereby blocking CSF-1 binding to its receptor and suppressing CSF-1-induced c-fms

signaling. This results in the suppression of recruitment and activation of tumor

associated macrophages (TAM) within the tumor microenvironment. This eventually

leads to a decrease in tumor growth. c-fms, a transmembrane protein belong ing to the

tyrosine kinase family, is overexpressed in certain tumor cell types and plays an essential

role in macrophage differentiation and regulation of cell proliferation. The presence of

TAM is correlated with tumor proliferation, invasion and a poor prognosis. 